\title{
Round objects
}

\section{Planets are spherical, and the International Astronomical Union's attempt to make this part of their definition has merit.}

T here was once a prissy British civil servant who, when he came across a passage in a memo that displeased him, wrote "round objects" in the margin as a synonym for something ruder. This arch circumlocution was lost on the bluff minister he served, who fired back a query as to who this Round fellow was, and why he objected so much.

We can expect there to be plenty of members of the International Astronomical Union (IAU) who, reading the proposed new definition of a planet offered to them by their executive committee, will want to scrawl something equally rude and rather blunter in the margin - and will want to make their objections heard, possibly quite vociferously, at their general assembly in Prague this week (see page 724).

We understand and, to some extent, sympathize. But we would suggest that, instead, they acquiesce in the new definition, which will have the effect of increasing the number of planets in the Solar System to 12, and open the doors to more. They should do this for two reasons: it is not a bad definition; and it will at least stop the rumbling debate over the status of Pluto.

In the 1990s, it became clear that Pluto, the most newly discovered planet, was the most conspicuous of a crowd of icy 'trans-neptunian objects' (TNOs), some of which might well be larger. There was an obvious historical parallel to this situation with asteroids in the nineteenth century. When it was found that there were dozens of asteroids, Ceres, the largest and first discovered, was demoted from its position as a proper planet; it is now a 'minor planet' along with all the other asteroids. Pluto, it was argued by analogy, should be a minor planet with the rest of the TNOs on similar grounds.

This proposal sparked a degree of public debate that irritated many astronomers, who felt that the question of whether a particular body gets called a planet or not is of no scientific interest whatsoever. Still, the IAU decided that it should try and resolve the matter: planets

\section{Revival in Iran}

\section{Whatever its motivation, Iran's support for education and science is to be welcomed.}

n eleventh-century Persia, it is said that three school friends pledged to serve their country and share their fortunes. Very different fortunes, it turned out.

Nizam al-Mulk became prime minister to two consecutive Persian kings. He built a network of roads across the country, and established the chain of 'Nizamiyya' schools, which taught theology, science and mathematics, adhering to a national curriculum.

Hassan-i Sabbah became the head of a fanatical religious group, the loom large in the public imagination, and it seemed only reasonable for astronomers to be able to say whether a new discovery (or for that matter an old friend) was a planet or not.

The IAU's proposal is that the term 'planet' should apply to an object that has a sufficiently strong gravitational field to have pulled itself into a spherical shape, that is in orbit around a star, but that is not a star itself. This lets in Pluto and $2003 \mathrm{UB}_{313}$, a TNO that is a touch bigger and not yet equipped with an IAU-approved name. It also readmits Ceres. And in the most peculiar aspect of the whole business, Charon, previously considered to be a moon of Pluto, will become a planet in its own right. Moons, however spherical, will remain satellites, not planets, in the IAU's eyes. But because the centre of mass of the Pluto-Charon system lies outside the body of Pluto, Charon, although tiny compared with, say, Neptune's moon Triton, qualifies as a planet.

Nine more TNOs, and three more asteroids, will become candidate planets, pending further investigation of how spherical they are. More planetary TNOs may follow, when discovered. To

"All this will doubtless lead to ructions, but it is at least a coherent approach, and it has a fairly clear basis in physical properties." tidy things up, the minor planets will get renamed: those that don't have enough of a gravitational grip on themselves to be proper planets will now be 'small Solar System bodies'.

All this will doubtless lead to ructions. But it is at least a coherent approach, and it has a fairly clear basis in physical properties. It has been convenient to have a small and easily memorized number of planets in the Solar System, but convenience is not the only thing that counts. The effects of mass define (unofficially) the upper limits of the planetary realm; anything big enough for fusion is a star. It is fitting, then, that mass should define the lower limit too. This, we think, adds up to a case for IAU members to accept the proposal.
Hashshashin, which operated an almost independent government, protected by a string of castles. The many attempts by Persian kings to overthrow the Hashshashin failed, and Nizam al-Mulk was eventually assassinated by Sabbah's followers.

Omar Khayyam became the greatest astronomer and mathematician of his age. He invented, for example, the Khayyam triangle better known as the Pascal triangle, after Blaise Pascal who described it hundreds of years later. Khayyam also provided his country with a solar calendar, more accurate than the gregorian calendar we use today. And he became one of Persia's most popular poets.

In the millennium since the three school friends parted company, the country we now know as Iran has witnessed a sometimes glorious, often sad, political history. Along with the rest of the Middle East, Iran's scientific power declined as Europe's ascended with the 
Renaissance. But the nation's cultural respect for study never died.

Science regained its foothold during the 1970s, under the Shah, even though his oppressive regime drove many intellectuals into exile. It faltered at the start of the Islamic revolution in 1979, but gained momentum in the 1990s when Iran became the most scientifically productive country in the Middle East apart from Israel. About 4,000 papers from Iran were published in 2005, according to the Institute for Scientific Information, compared with just over 500 in 1995. (Nature's first all-Iranian research paper was published last week.)

Perhaps the rise of science relates to the importance that Iran's government attaches to the development of nuclear technology. Many regard Iran's interest in these technologies with extreme suspicion. Nonetheless, Iran's embrace of science should be welcomed.

The educated young in Iran will still go their own individual ways, usually for good, sometimes for bad. But there is once again the opportunity for a privileged few to shine as scientists, if they can cope with the low pay and poor infrastructure that prevail outside the handful of elite institutions, and can sidestep the many problems caused by US sanctions.

One practical advantage for science in Muslim countries is the lack of direct interference of religious doctrine, such as exists in many Christian countries. There has never, for example, been a debate about darwinian evolution, and human embryonic stem-cell research is constrained by humanistic rather than religious ethics. The Royan Institute in Iran was the first in the Middle East to develop a human embryonic stem-cell line, using spare embryos from its in vitro fertilization programme.

The recent dramatic rise in scientific productivity coincided with the relaxing of a stern Islamic regime under reformist president Mohammad Khatami. When hard-line Islamist Mahmoud Ahmadinejad was elected president last year, some scientists felt nervous, especially, no doubt, when he replaced the presidents of all the universities with worryingly inexperienced people. But the regime has so far shown a strong commitment to higher education. One of its first acts was to wipe out the debts accrued by universities, where female students now outnumber males, even in some areas of hard science. Ahmadinejad has also taken significant steps to prepare for an expansion of university student numbers. And he has not made cuts to research funds, which had increased over the past decade.

But will he maintain growth, given other pressing priorities in today's Iran? If not, many young scientists trained in the recent good years and now undertaking postdoctoral research abroad will have no prospects if they return home. An opportunity would be lost. So here's hoping that he avoids the need for these lines of Khayyam as a lament:

Alas that spring should vanish with the rose

That youth's sweet-scented manuscript should close!

\section{Preventing cancer}

\section{More support is required to tackle obesity as a means of cancer prevention.}

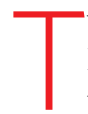
wenty-five years ago, a landmark study by Richard Doll and Richard Peto concluded that $75-80 \%$ of cancers diagnosed in the United States in 1970 might theoretically have been prevented by altering environmental factors such as smoking, alcohol consumption and diet (R. Doll \& R. Peto J. Natl Cancer Inst. 66, 1191-1308; 1981). More recent work has added obesity and physical inactivity to the list of factors that increase cancer risk. Today, tobacco use accounts for $30 \%$ of cancers in the United States, obesity accounts for $15 \%$ and poor diet for up to $25 \%$. Clearly, while avidly pursuing promising avenues of therapy (see page 735), the biomedical community and policy-makers need to tackle cancer prevention with just as much zeal.

The success of campaigns to combat melanoma and lung cancer are testaments to the impact that prevention can make. For example, the Australian government's exhortation to "slip on a shirt, slop on a sunscreen, slap on a hat" has led to melanoma having less of a health impact in Australia than in cloudier countries such as Britain. The incidence of smoking-related cancers has dropped sharply since the 1990s - the delayed effects of anti-smoking campaigns started in the 1960s and 1970s.

But much still needs to be done. Tobacco remains a problem, especially in the developing world, where consumption is climbing. The next biggest threat facing the developed world is the growing epidemic of obesity. In the United States and Europe, for example, around two-thirds of the population is either overweight or obese. Research into how people form dietary and exercise habits will help to inform intervention campaigns, and research on nutrition will help to determine why a vegetable-rich, low-saturated-fat diet seems to provide protection against cancer. Studies on genetic susceptibility could one day help us all to tailor our lifestyles to suit our risk profiles.

But such research is likely to have little effect unless policy-makers are prepared to go further than just educating the public. Avoiding the Sun is straightforward and cheap. The same cannot be said of factors that affect obesity. Once associated with wealth and excess, obesity now disproportionately affects the poorer sections of society, because high-calorie, low-nutrient, processed food is often much more easily accessible than healthy alternatives. Governments need to help ensure that eating the recommended five portions of fruit and vegetables a day is a realistic aim for everyone.

Physical activity needs to be tack-

\section{"The success of campaigns to combat melanoma and lung cancer are testaments to the impact that prevention can make."} led too. Encouraging children and adults to take up sport is a start, but policies that encourage people to build exercise into their daily lives - town planning that makes walking to the shops or cycling to work easier and safer, for example - are likely to have a longerlasting impact.

Our modern lifestyles are increasingly at odds with the environment in which our physiology originally evolved. Finding a truce between the two would go a long way to reducing the burden of diseases, such as cancer, that result. 